\title{
Altered canonical Wingless-Int signaling in the ovine fetal lung after exposure to intra-amniotic lipopolysaccharide and antenatal betamethasone
}

\author{
Elke Kuypers ${ }^{1-3}$, Monique G.M. Willems ${ }^{1-3}$, Jennifer J.P. Collins ${ }^{1-4}$, Tim G.A.M. Wolfs ${ }^{1-3}$, llias Nitsos ${ }^{5,6}$, J. Jane Pillow ${ }^{5}$, \\ Graeme R. Polglase ${ }^{5,6}$, Matthew W. Kemp ${ }^{5}$, John P. Newnham ${ }^{5}$, Tammo Delhaas ${ }^{1-3}$, Alan H. Jobe ${ }^{5,7}$, Suhas G. Kallapur ${ }^{5,7}$ \\ and Boris W. Kramer ${ }^{1-3,5}$
}

\begin{abstract}
BACKGROUND: Antenatal inflammation and maternal corticosteroids induce fetal lung maturation but interfere with late lung development. Canonical Wingless-Int (Wnt) signaling directs lung development and repair. We showed that intraamniotic (IA) lipopolysaccharide (LPS) exposure disrupted developmental signaling pathways in the preterm lamb lungs. Therefore, we hypothesized that pulmonary Wnt signaling was altered by exposure to IA LPS and/or antenatal corticosteroids. METHODS: Ovine fetuses were exposed to IA LPS, maternal intramuscular betamethasone, a control saline injection, or a combination thereof at 107 and/or 114 d gestational age (term $=150 \mathrm{~d}$ gestational age) before delivery at $121 \mathrm{~d}$ gestational age.
\end{abstract}

RESULTS: IA LPS exposure decreased the lung expression of lymphoid enhancer-binding factor 1 (LEF1), a major Wnt pathway effector. WNT1, WNT4, and downstream messenger $\beta$-catenin decreased after LPS exposure. WNT76 mRNA increased fourfold $14 \mathrm{~d}$ post-LPS exposure. Betamethasone treatment $7 \mathrm{~d}$ before LPS exposure prevented the reduction in LEF1 expression, whereas betamethasone administration after LPS normalized the LPS-induced increase in Wnt7b mRNA.

CONCLUSION: IA LPS exposure decreased canonical Wnt signaling in the developing lung. Antenatal corticosteroids before or after IA inflammation had different effects on pulmonary Wnt signaling. This study provides new insights into possible mechanisms by which prenatal inflammation affects lung development and how corticosteroid can be beneficial in this setting.

$P$ reterm birth is frequently initiated by chorioamnionitis, an intrauterine inflammation of the chorioamniotic membranes (1). Exposure to antenatal inflammation may contribute to adverse neonatal outcomes in preterm infants including lung injury (2). As a result, bronchopulmonary dysplasia (BPD) can develop, which is characterized by fewer and larger alveoli due to an arrested development of alveolar septation and impaired pulmonary microvascular development (3). The corticosteroid betamethasone is routinely administered to mothers at risk for preterm delivery to improve neonatal survival (4). Although corticosteroids accelerate lung maturation, they also inhibit the outgrowth of secondary septa and therefore can interfere with late lung development (5).

Wingless-Int (Wnt) signaling plays a role in lung development by regulating epithelial and mesenchymal interactions in an autocrine and paracrine manner $(6,7)$. The canonical Wnt pathway signals through $\beta$-catenin (6). In the absence of Wnt ligands, $\beta$-catenin is phosphorylated by glycogen synthase kinase (GSK)-3 $\beta$, ubiquitinated, and degraded. Upon activation of the Wnt cascade, GSK-3 $\beta$ becomes phosphorylated and inhibited (8). Consequently, $\beta$-catenin phosphorylation is prevented, and the amount of cytosolic $\beta$-catenin increases (8). The accumulated $\beta$-catenin translocates to the nucleus and regulates gene transcription via formation of an active transcription complex with T-cell-specific transcription factor/ lymphoid enhancer-binding factor (LEF) family members (9). The importance of Wnt signaling during lung development was demonstrated in several transgenic models of different Wnt isoforms. Wnt $2^{-/-}$mice have severe lung hypoplasia and a poorly developed lung mesenchyme at birth (10). Similarly, knockout of Wnt7b in mice results in lung hypoplasia and perinatal death due to respiratory failure (11). Reduced pulmonary Wnt7b expression impairs mesenchymal growth and vascular development (11). Wnt 1 and Wnt 4 are associated with the expression of matrix metalloproteinases, which are known to be involved in lung epithelial repair processes and pulmonary fibrosis $(12,13)$.

Previously, we showed that exposure to intra-amniotic (IA) lipopolysaccharide (LPS) induced pulmonary inflammation in fetal lambs and influenced lung developmental pathways $(14,15)$. IA LPS exposure altered the expression of the lung structural proteins elastin and collagen, leading to a simplified 


\section{Articles | Kuyperset al.}

lung structure as seen in BPD patients (16). Betamethasone pre or posttreatment partially counteracted these effects (14). However, little is known about the molecular signaling cascades by which perinatal events affect late lung development. Rodent models of neonatal hyperoxia-induced lung injury have recently related perturbations in the Wnt cascade with developmental alterations in postnatal lung development, similar to BPD (17). In this study, we investigated the effects of intrauterine inflammation, which is implicated in the pathogenesis of BPD, on canonical Wnt signaling in a preterm ovine model in which the pulmonary development closely resembles the early alveolarization stage in extremely preterm infants (18). We hypothesized that Wnt signaling was altered in ovine fetal lungs exposed to in utero inflammation and/or antenatal corticosteroids. For this purpose, we examined different Wnt isoforms and downstream effectors of the canonical Wnt pathway in the lungs of fetal sheep that were exposed to IA LPS and/or antenatal corticosteroids.

\section{RESULTS}

\section{Pulmonary LEF1 Expression}

To investigate changes in pulmonary Wnt signaling, we determined the mRNA levels and immunoreactivity of LEF1, the major downstream effector of the Wnt pathway, the nuclear expression of which increases upon Wnt activation (19). Exposure to LPS 7 or $14 \mathrm{~d}$ before preterm delivery resulted in decreased LEF1
mRNA levels (Figure 1a) and LEF1 protein immunoreactivity (Figure 1b). LEF1 immunoreactivity was mainly localized in the nucleus of the alveolar cells in control animals. LPS-exposed animals showed reduced nuclear LEF1 staining in the alveoli. Betamethasone treatment before the LPS exposure but not after LPS exposure prevented the decrease in LEF1. Representative images of positive LEF1 staining are shown for controls (Figure 1c) and 14-d LPS-exposed lungs (Figure 1d).

\section{Lung mRNA Levels of WNT Isoforms}

The mRNA expression of different WNT isoforms was measured to characterize the upstream changes in Wnt signaling after IA LPS exposure. WNT1 mRNA levels in the fetal lung decreased by $90 \% 7 \mathrm{~d}$ after the exposure to LPS as compared with controls (Figure 2a). Exposure to LPS at $14 \mathrm{~d}$ followed by betamethasone exposure at $7 \mathrm{~d}$ before delivery increased WNT1 mRNA levels when compared with 14-d LPS exposure alone. WNT2 mRNA decreased by $80 \% 14 \mathrm{~d}$ after LPS exposure irrespective of betamethasone posttreatment (Figure 2b). WNT4 mRNA levels were significantly decreased in all LPS-exposed treatment groups as compared with controls (Figure 2c). In contrast, WNT7b levels increased fourfold 14 $\mathrm{d}$ after LPS exposure as compared with controls (Figure 2d). Treatment with betamethasone $7 \mathrm{~d}$ after the LPS exposure normalized this increase. However, in this group, there was still a trend toward increased WNT7b expression.
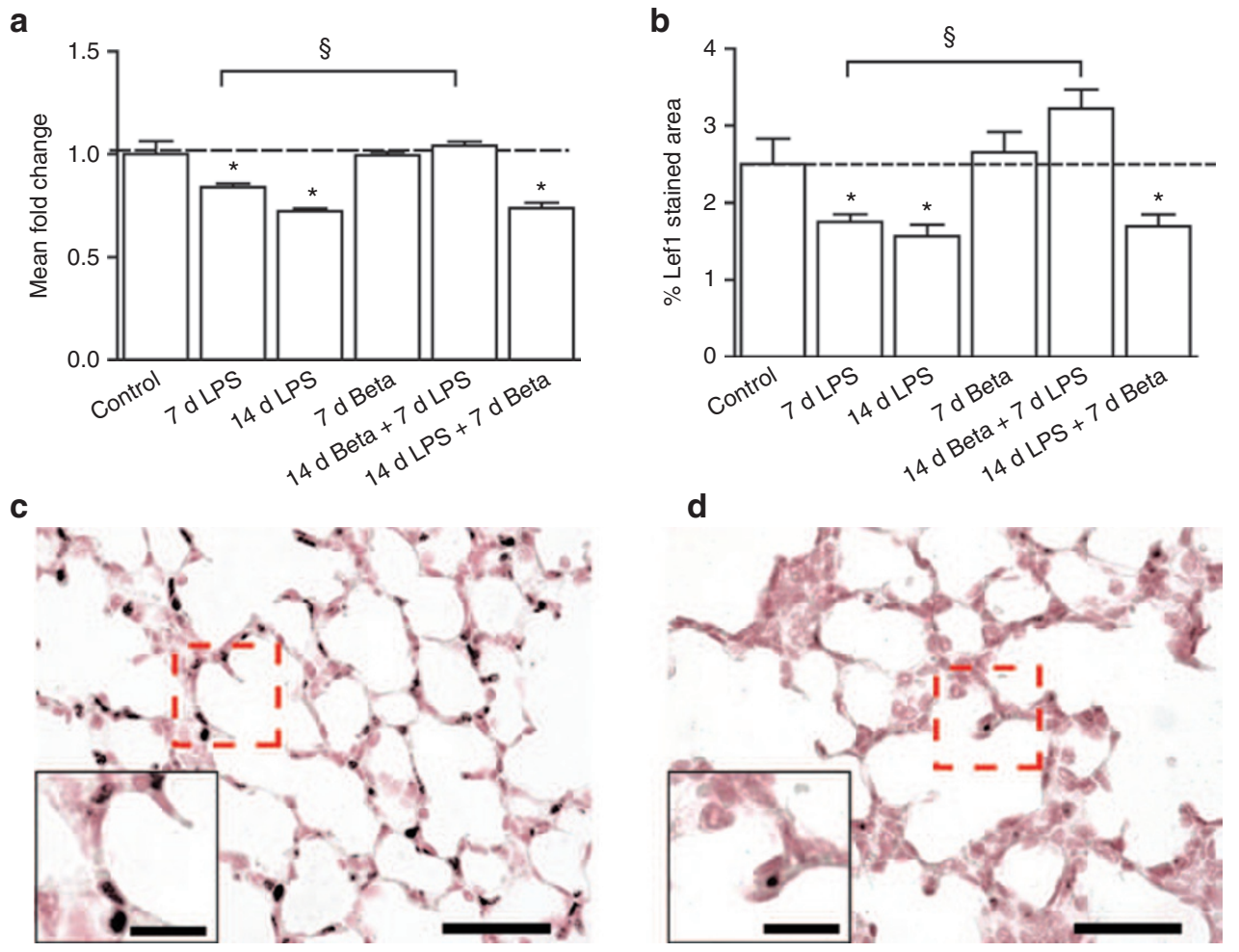

Figure 1. Pulmonary LEF1 expression. (a) LEF1 mRNA: mRNA levels of LEF1 were decreased 7 and $14 \mathrm{~d}$ after LPS exposure. Combined exposure to 14-d LPS and 7-d Beta also resulted in decreased LEF1 mRNA levels. (b) LEF1 expression: the area fraction (\%) of LEF1 immunoreactivity in the lung decreased after exposure to LPS 7 or $14 \mathrm{~d}$ before delivery. Beta treatment before the LPS exposure but not after LPS exposure prevented the decrease in LEF1. (c) LEF1 staining (black staining) in the fetal lung tissue (red counterstaining) was detected in the nucleus of the alveoli in control animals. (d) 14-d LPS-exposed animals showed reduced nuclear LEF1 staining. Scale bar $=50 \mu \mathrm{m}$; scale bar, insert $=20 \mu \mathrm{m}$. ${ }^{*} P<0.05 \mathrm{vs}$. controls and ${ }^{\S} P<0.05$ between experimental groups using a one-way ANOVA with Tukey's post hoc test. Beta, betamethasone; LPS, lipopolysaccharide. 
a

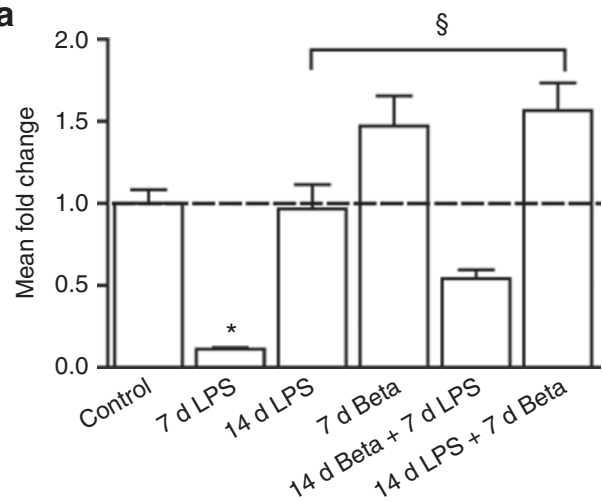

C

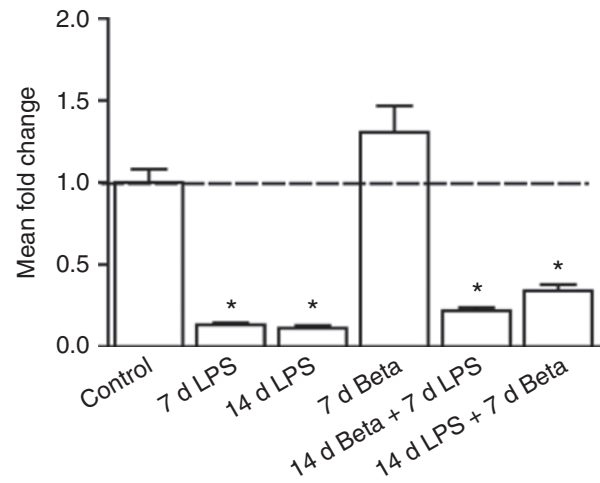

b
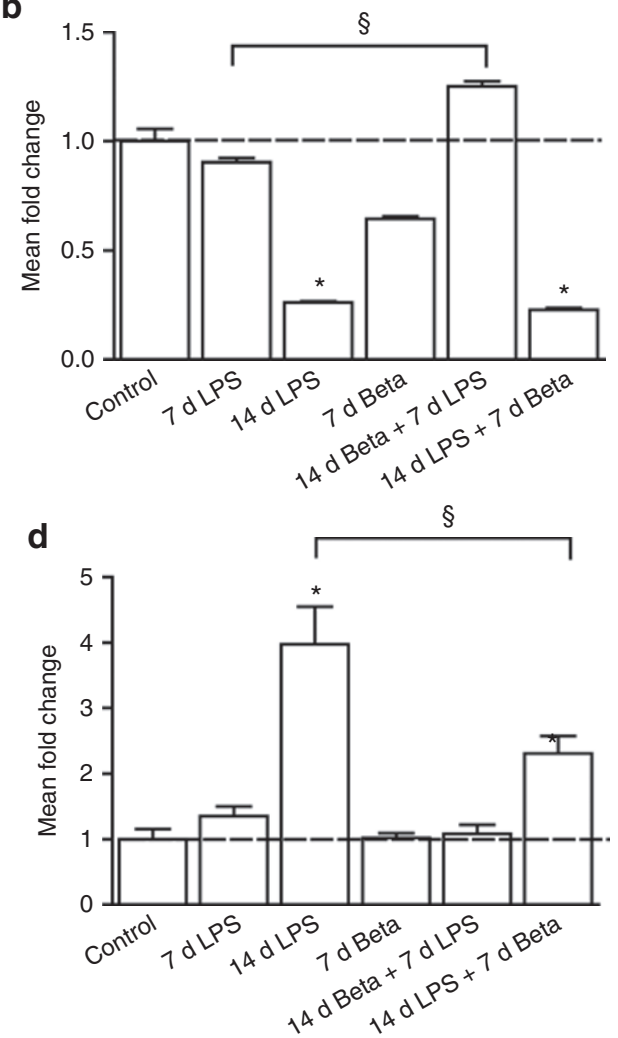

Figure 2. Lung mRNA levels of WNT isoforms. (a) Wnt1 mRNA: the mRNA levels of WNT1 decreased ninefold $7 \mathrm{~d}$ after LPS exposure as compared with controls. (b) Wnt2 mRNA: WNT2 mRNA decreased after $14 \mathrm{~d}$ of LPS exposure irrespective of the betamethasone treatment. (c) Wnt4 mRNA: levels of WNT4 mRNA decreased in all LPS-exposed groups as compared with controls. (d) Wnt7b mRNA: mRNA levels of WNT7b increased nearly fourfold $14 \mathrm{~d}$ after LPS exposure as compared with controls. This increase was prevented if betamethasone (Beta) was administered $7 \mathrm{~d}$ after LPS exposure. ${ }^{*} P<0.05$ vs. controls and ${ }^{\S} P<0.05$ between experimental groups using a one-way ANOVA with Tukey's post hoc test. LPS, lipopolysaccharide.

\section{$\beta$-Catenin and GSK-3 $\beta$ Expression in the Fetal Lung}

LPS and/or betamethasone exposure did not change CTNNB1 mRNA or GSK3B mRNA levels in the fetal lung (data not shown). $\beta$-Catenin protein expression decreased after the exposure to LPS $7 \mathrm{~d}$ before delivery and after exposure to LPS followed by betamethasone posttreatment (Figure 3a). GSK$3 \beta$ protein expression in the fetal lung did not change significantly in any of the experimental groups (Figure $3 \mathbf{b}$ ).

\section{DISCUSSION}

Although epidemiological and experimental studies have demonstrated a clear correlation between prenatal inflammation and altered fetal lung development $(20,21)$, little is known about the molecular pathways mediating these effects. We found that exposure to IA LPS downregulated the Wnt pathway as illustrated by decreased nuclear LEF1 immunoreactivity and decreased $\beta$-catenin protein expression. $\beta$-Catenin signaling during pulmonary development is necessary for growth and differentiation of pulmonary epithelial cells (22). Subsequently, inhibition of Wnt signaling can lead to impaired branching and defects in vascular development in the lung (11). Previously, we demonstrated reduced alveolar septation following LPS exposure in this animal model (14).

In this study, we show aberrant Wnt signaling in this model of disrupted lung morphology after exposure to IA inflammation. Of the four WNT isoforms we measured, WNT1 and WNT4 had similar patterns of decreases as LEF1 after IA LPS exposure, suggesting that these changes are responsible for the decreased LEF1 expression. However, differential expression patterns of these WNT isoforms and others occur both in lung development and in lung disease $(23,24)$. The net outcome of these changes is dependent not only on the Wnt receptor and the affinity of the Wnt isoform for that receptor $(25,26)$ but also on the cross talk of Wnt components with other signaling pathways such as the transforming growth factor- $\beta$ pathway $(15,27)$. Interestingly, $14 \mathrm{~d}$ after the exposure to LPS, $W N T 7 b$ mRNA levels were upregulated. These relatively late effects may represent a response of the developing lung to repair the damage from IA LPS-induced inflammation. Wnt signaling can stimulate tissue remodeling, cell migration, and wound healing in the lung. Activation of the Wnt pathway in alveolar type II cells promotes epithelial survival and differentiation toward alveolar epithelial cells after lung injury (28). $\beta$-Catenin can induce fibroblast growth factor (FGF)-10 expression in parabronchial smooth muscle cell progenitors, which help to repair the damaged lung epithelium (29). We previously showed in this animal model that exposure to IA LPS was accompanied by increased levels of FGF10 in the fetal lung $14 \mathrm{~d}$ after the injection (14). Canonical Wnt signaling may stimulate FGF10 expression 
a
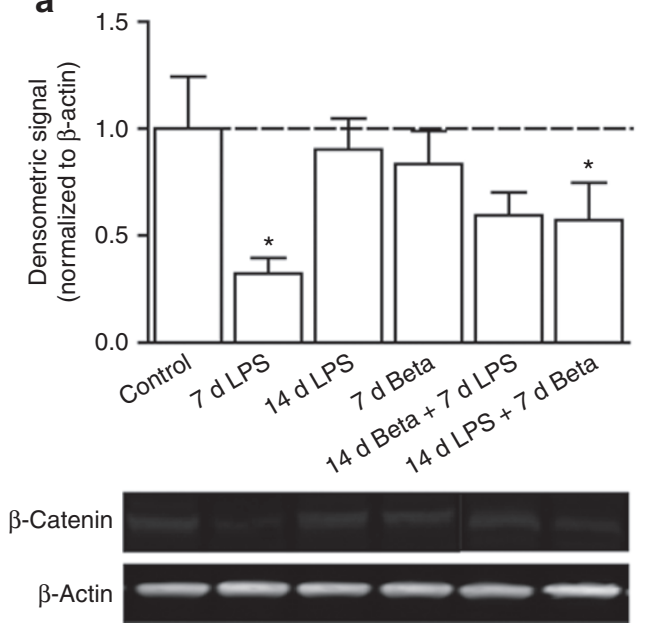

b

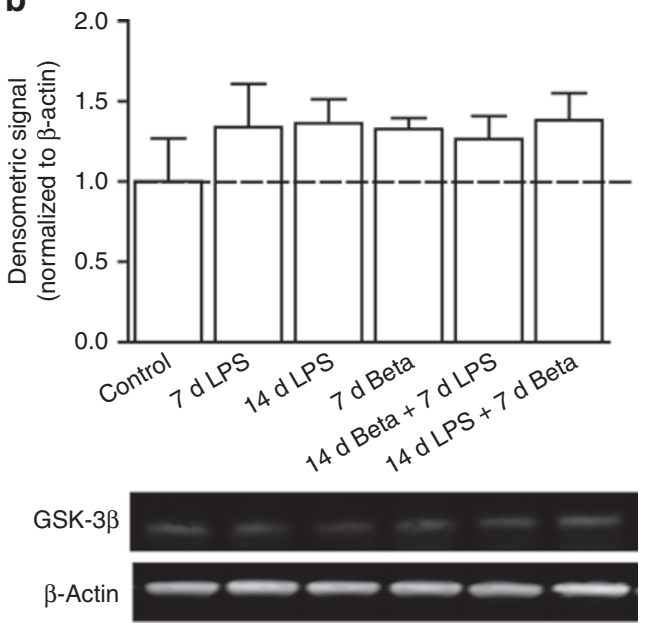

Figure 3. $\beta$-Catenin and GSK-3 $\beta$ expression in the fetal lung. (a) $\beta$-Catenin expression. $\beta$-Catenin protein expression decreased by two-thirds in fetal

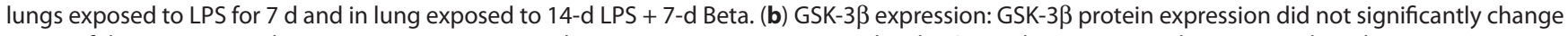
in any of the experimental groups. * $P<0.05$ vs. controls using a one-way ANOVA with Tukey's post hoc test. GSK, glycogen synthase kinase; LPS, lipopolysaccharide.

and subsequent myofibroblast differentiation in the ovine fetal lung after exposure to IA inflammation. Although canonical Wnt signaling plays a key role in the repair phase after lung injury, aberrant activation of the Wnt pathway can have deleterious consequences. Increased canonical Wnt signaling is seen in fibrotic diseases such as idiopathic fibrosis and ventilation-induced lung injury $(24,30)$. It, however, remains to be determined if Wnt signaling remains perturbed in this model, and if so, how persistently altered Wnt signaling affects lung development beyond the fetal environment.

Lung development is affected in utero by both chorioamnionitis and antenatal corticosteroids. Nevertheless, the interaction between both the exposures is less understood. We previously reported that corticosteroids given $7 \mathrm{~d}$ before the exposure to IA LPS inhibited pulmonary inflammation and injury in the ovine fetal lung (31). Here, we further demonstrate that corticosteroid treatment before the exposure to LPS attenuated the decrease in LEF1 expression, which is the main effector of the canonical Wnt pathway. A single dose of antenatal corticosteroid $7 \mathrm{~d}$ after the LPS exposure normalized some of the investigated Wnt signaling components in the fetal lung. Others have reported interactions that are consistent with these results. Stimulation of the glucocorticoid receptor can activate GSK$3 \beta$, which in turn increases $\beta$-catenin breakdown and thus inhibits the Wnt pathway (32). In addition, the glucocorticoid receptor can directly decrease Wnt signaling by binding to the T-cell-specific transcription factor- $\beta$-catenin complex (33).

Chorioamnionitis and antenatal corticosteroids are common exposures for the preterm fetus. Our model allowed testing their interaction in a time-dependent manner, which is not possible in the clinical setting, where chorioamnionitis might be present but is usually clinically silent. A recent prospective cohort study demonstrated that antenatal corticosteroids reduced adverse outcomes in preterm infants with histological chorioamnionitis, irrespective of whether inflammation was present on the maternal side only or the fetus was involved (34), which was confirmed in a meta-analysis (35). Clinical timing of antenatal corticosteroid therapy is additionally influenced by the presence of premature rupture of membranes. In the setting of premature rupture of membranes, antenatal corticosteroids substantially reduce the risks of adverse outcomes, such as neonatal respiratory distress syndrome, without significantly increasing the risk of infection for mother or baby (36). However, premature rupture of membranes itself is strongly associated with intrauterine inflammation, and the rate of histological chorioamnionitis and funisitis appears to increase with prolonged latency between premature rupture of membranes and delivery (37). Therefore, we speculate that this group of preterm infants might benefit from antenatal corticosteroids because of its positive influence on subsequent inflammation.

This is the first report to show altered Wnt signaling after antenatal inflammation in the fetal lung. However, future in vitro and in vivo studies are needed to demonstrate a causal link between the presence of inflammation and disturbances in this pathway and subsequently late lung development. Although we were not able to perform an in-depth analysis of the investigated pathway due to lack of specific reagents, these initial observations of changes in Wnt signaling do provide interesting options for possible intervention strategies because redirecting Wnt signaling in the fetal lungs may provide beneficial outcomes for the premature lung. Inhibition of GSK3- $\beta$ by a pharmacological modulator SB216763 resulted in reduced pulmonary inflammation and improved alveolarization in a hyperoxic rodent model of BPD (38). Future studies will be needed to show if and how pharmacological modulation of the Wnt pathway can redirect late lung development after exposure to chorioamnionitis. In conclusion, our results demonstrate that fetal lung exposure to LPS can decrease Wnt signaling and that maternal corticosteroid administration can partially prevent these changes. Thereby this study helps to provide insight into the beneficial effects of antenatal corticosteroid treatment on the fetal lung in the setting of intrauterine inflammation. 


\section{METHODS}

\section{Animal Model and Sampling Protocol}

All animal experiments were approved by the Animal Ethics Committees of Cincinnati Children's Hospital Medical Center and the University of Western Australia (animal ethics protocol $\mathrm{RA} / 3 / 100 / 830)$. Time-mated Merino ewes with singleton fetuses were randomly divided into six treatment groups ( $n=5-8$ per group). The ewes received either: an IA injection of $10 \mathrm{mg}$ LPS (Escherichia coli, 055:B5; Sigma-Aldrich, St Louis, MO), an intramuscular injection of the corticosteroid betamethasone (Celestone Soluspan $0.5 \mathrm{mg} / \mathrm{kg}$ maternal weight; Schering-Plough, North Ryde, Australia), a control saline injection, or a combination thereof at 107 and/or 114 d gestational age (Figure 4). Because betamethasone treatment can induce preterm delivery in sheep, all ewes also received a single intramuscular injection of medroxyprogesterone acetate (Depo-Provera $150 \mathrm{mg}$; Kenral, New South Wales, Australia) at 100 d gestational age to decrease the risk of preterm labor (39). Lambs were surgically delivered preterm at $121 \mathrm{~d}$ gestational age (term is $150 \mathrm{~d}$ gestational age) and were humanely killed. The lungs were removed, and samples of right caudal lobe (right lower lobe) tissue were snap frozen. The whole right cranial lobe (right upper lobe) was inflation fixed for $24 \mathrm{~h}$ in $10 \%$ buffered formalin at a pressure of $30 \mathrm{~cm} \mathrm{H}_{2} \mathrm{O}$ and processed for paraffin embedding.

\section{RNA Extraction and Quantitative Real-Time PCR}

Total RNA was extracted from snap-frozen right lower lobe tissue using the SV Total RNA Isolation System (Z3100, Promega, Madison, $\mathrm{WI}$ ), according to the manufacturer's protocol. A DNase treatment was performed to eliminate possible genomic DNA contamination, using the RQ1 RNase-Free DNase kit (M6101; Promega). cDNA was synthesized with a Transcriptor First Strand cDNA Synthesis Kit using Anchored-oligo(dT)18 Primers (04379012001; Roche Applied Science, Penzberg, Germany), according to the manufacturer's protocol. Primers were created based on genome sequences of Bos taurus and Ovis aries (Table 1). Dilution experiments were performed to ensure proper PCR amplification efficiency of the primers. Quantitative PCR reactions were run in duplicate for each primer set at the appropriate melting temperature for 45 cycles with a LightCycler 480 Instrument (Roche Applied Science) and LightCycler 480 SYBR Green I Master mix (4707516001; Roche Applied Science). Quantitative PCR results were normalized to the housekeeping gene ovine ribosomal protein S15 (ovRPS15). Mean fold changes in mRNA expression, as compared with control animals, were calculated using the $\Delta \Delta C_{\mathrm{t}}$ method (40).

\section{Immunohistochemistry}

Paraffin-embedded right upper lobe lung tissue sections $(4 \mu \mathrm{m})$ were deparaffinized using a xylene and ethanol $(100,96$, and $70 \%)$ series. Incubation in sub-boiling citrate buffer $(10 \mathrm{mmol} / \mathrm{l}, \mathrm{pH} 6.0)$ for $30 \mathrm{~min}$

\begin{tabular}{|c|c|c|c|c|}
\hline Beta & 100 & 107 & 114 & $121 \mathrm{dGA}$ \\
\hline Control (5) & Depo-Provera (IM) & Saline (IM) & Saline (IM) & Delivery \\
\hline 7 d LPS (8) & Depo-Provera (IM) & Saline (IM) & LPS (IA) & Delivery \\
\hline 14 d LPS (8) & Depo-Provera (IM) & LPS (IA) & Saline (IM) & Delivery \\
\hline 7 d Beta (7) & Depo-Provera (IM) & Saline $(I A)$ & Beta (IM) & Delivery \\
\hline 14 d Beta + 7 d LPS (6) & Depo-Provera (IM) & Beta (IM) & LPS (IA) & Delivery \\
\hline 14 d LPS + 7 d Beta (8) & Depo-Provera (IM) & LPS (IA) & $\beta(\mathrm{IM})$ & Delivery \\
\hline
\end{tabular}

Figure 4. Study design. Ovine fetuses were exposed to intra-amniotic (IA) LPS, a maternal intramuscular (IM) betamethasone (Beta) injection, a control saline injection, or a combination thereof at 107 and/or $114 \mathrm{~d}$ gestational age (dGA) (term $=150 \mathrm{dGA})$. All ewes also received an intramuscular injection of medroxyprogesterone acetate (Depo-Provera) at $100 \mathrm{dGA}$ to decrease the risk of preterm labor. Lambs were delivered preterm by cesarean section at $121 d G A$. LPS, lipopolysaccharide.

Table 1. Primers used for RT-PCR

\begin{tabular}{|c|c|c|c|c|}
\hline Gene & & Sequence $\left(5^{\prime}-3^{\prime}\right)$ & Amplicon size (bp) & Temperature $\left({ }^{\circ} \mathrm{C}\right)$ \\
\hline \multirow[t]{2}{*}{ WNT1 } & $\mathrm{Fw}$ & ATTTATCTTCGCCATCACCTC & 123 & 64 \\
\hline & $\mathrm{Rv}$ & ATTCGATGGAGCCCTCTG & & \\
\hline WNT2 & $\mathrm{Rv}$ & ACCTCTTTACAGCCTTCCTGCC & & \\
\hline WNT4 & Fw & GCTGGGCTCCAAGTACACC & 241 & 60 \\
\hline \multirow[t]{2}{*}{ WNT7b } & $\mathrm{Fw}$ & TGCACTCCAGCTTCATGCGC & 60 & 58 \\
\hline & $\mathrm{Rv}$ & ACCTGCACAACAACGAGGCG & & \\
\hline \multirow[t]{2}{*}{ CTNNB1 } & $\mathrm{Fw}$ & CTATTGAAGCCGAGGGAG & 200 & 60 \\
\hline & $\mathrm{Rv}$ & CAAGATCAGCAGTCTCATTCC & & \\
\hline GSK3B & Fw & CGAGACACACCTGCACTCTT & 157 & 60 \\
\hline \multirow[t]{2}{*}{ ovRPS15 } & Fw & CGAGATGGTGGGCAGCAT & 93 & 60 \\
\hline & $\mathrm{Rv}$ & GCTTGATTTCCACCTGGTTGA & & \\
\hline
\end{tabular}

FW, forward; RT-PCR, real-time PCR; Rv, reverse. 
was used for antigen retrieval. To block endogenous peroxidase activity, slides were incubated in phosphate-buffered saline ( $\mathrm{pH}$ 7.4) with $0.5 \%$ hydrogen peroxide $\left(\mathrm{H}_{2} \mathrm{O}_{2}\right)$ for $20 \mathrm{~min}$. Nonspecific binding of antibodies was prevented by incubating the sections with $10 \%$ normal goat serum (NGS) in phosphate-buffered saline. Sections were stained overnight at $4{ }^{\circ} \mathrm{C}$ with monoclonal rabbit anti-LEF1 antibody (1:100, 2230; Cell Signaling Technology, Danvers, MA). A negative control was included by incubating with $0.1 \%$ bovine serum albumin/phosphate-buffered saline instead of the primary antibody. After $1 \mathrm{~h}$ of incubation with biotinylated polyclonal swine antirabbit secondary antibody (1:200, E0353; Dako, Glostrup, Denmark), the immunostaining was augmented with the addition of a peroxidase-labeled ABC complex (1:500; Vectastain Elite ABC kit PK-6200; Vector Laboratories, Burlingame, CA). Immunostaining was visualized with Nickel-enhanced diaminobenzidine, and the sections were counterstained with $0.1 \%$ nuclear fast red solution.

Staining of the sections was evaluated by light microscopy (DM2000; Leica Microsystems, Wetzlar, Germany). The area fraction (\%) of LEF1 immunoreactivity was measured in six random images per section by a blinded observer by applying a standard threshold using a specifically designed algorithm in Leica QWin Pro V 3.5.1 software (Leica, Rijswijk, The Netherlands) and corrected for the total percentage of lung tissue measured.

\section{Western Blot}

For protein analysis, snap-frozen right lower lobe tissue was homogenized in ice-cold radioimmunoprecipitation assay buffer (R0278; Sigma-Aldrich) supplemented with $0.1 \%$ protease inhibitor cocktail (P9599; Sigma-Aldrich). Homogenates were centrifuged for $5 \mathrm{~min}$ at $12 \times$ relative centrifugal force. To determine protein concentrations, a Micro Bicinchoninic Acid Protein Assay Kit (23235; Thermo Fisher Scientific, Waltham, MA) was used with bovine serum albumin as a standard, according to the manufacturer's instructions. Samples were diluted in $5 \times$ sample buffer (consisting of glycerol, sodium dodecyl sulfate (SDS), $0.5 \mathrm{~mol} / \mathrm{l}$ Tris- $\mathrm{HCl}(\mathrm{pH} 6.8)+0.4 \%$ sodium dodecyl sulfate, bromophenol blue, dithiothreitol, and Milli-Q) and denatured by heating at $95{ }^{\circ} \mathrm{C}$ for $10 \mathrm{~min}$. Equal amounts of protein $(40 \mu \mathrm{g}$ per sample) were loaded on sodium dodecyl sulfate-polyacrylamide gels. Proteins were separated within $1.5 \mathrm{~h}(90 \mathrm{~V})$ by gel electrophoresis and transferred onto $0.2 \mu \mathrm{m}$ pore size Protran BA83 nitrocellulose membranes (10402495; Whatman, Dassel, Germany) within $1 \mathrm{~h}$ (350 mA). Membranes were blocked for $1 \mathrm{~h}$ with a 1:1 mixture of ODYSSEY Infrared Imaging System Blocking Buffer (927-40000; LI-COR, Lincoln, $\mathrm{NE})$ and Tris-buffered saline $(2.5 \mathrm{mmol} / \mathrm{l}, \mathrm{pH} 7.5)$ and incubated overnight at $4{ }^{\circ} \mathrm{C}$ with the following primary antibodies: monoclonal rabbit anti- $\beta$-catenin (1:1000; 9582, Cell Signaling Technology), monoclonal rabbit anti-GSK-3 $\beta$ (1:4000; 9315, Cell Signaling), or monoclonal mouse anti- $\beta$-actin (1:1000; A5441, Sigma-Aldrich). IRDye 800CW conjugated goat antirabbit (1:6000; 926-32211, LI-COR) or IRDye 680RD conjugated donkey antimouse (1:6000; 926-32222, LI-COR) were used as secondary antibodies $(1 \mathrm{~h})$. Protein bands were detected and analyzed using a LI-COR Odyssey Infrared Imager System. Results were normalized to the housekeeping gene $\beta$-actin.

\section{Data Analysis}

Statistical analysis was conducted using GraphPad Prism v5.0 software (GraphPad Software, La Jolla, CA). One-way ANOVA with Tukey's test for post hoc analysis was used to compare the groups. All data are presented as means \pm SEM. $P<0.05$ was considered to be significant.

\section{ACKNOWLEDGMENTS}

We thank Hilde Laeremans, Ramon Langen, and Nicky Pansters for their advice and assistance. Also, we thank Dennis Kruk, Nico Kloosterboer, Richard Dalton, Joe Derwort, Masatoshi Saito, Clare Berry, Carryn McLean, Shaofu Li, and Jennifer Henderson for excellent technical support.

\section{STATEMENT OF FINANCIAL SUPPORT}

This study was supported by the National Institutes of Health (Bethesda, MD) grant HD-57869 (to S.G.K.); National Health and Medical Research Council of Australia; the Women and Infants Research Foundation, Western Australia; Veni BWK 016.096.141 from the Dutch Scientific Research Organization; and the Research School for Oncology and Developmental Biology (GROW), Maastricht University.
Disclosure: None of the authors have a conflict of interest.

\section{REFERENCES}

1. Goldenberg RL, Hauth JC, Andrews WW. Intrauterine infection and preterm delivery. N Engl J Med 2000;342:1500-7.

2. Gantert M, Been JV, Gavilanes AW, Garnier Y, Zimmermann LJ, Kramer BW. Chorioamnionitis: a multiorgan disease of the fetus? J Perinatol 2010;30:Suppl:S21-30.

3. Jobe AH, Bancalari E. Bronchopulmonary dysplasia. Am J Respir Crit Care Med 2001;163:1723-9.

4. Roberts D, Dalziel S. Antenatal corticosteroids for accelerating fetal lung maturation for women at risk of preterm birth. Cochrane Database Syst Rev 2006:CD004454.

5. Polglase GR, Nitsos I, Jobe AH, Newnham JP, Moss TJ. Maternal and intraamniotic corticosteroid effects on lung morphometry in preterm lambs. Pediatr Res 2007;62:32-6.

6. Weng T, Liu L. The role of pleiotrophin and beta-catenin in fetal lung development. Respir Res 2010;11:80.

7. Königshoff M, Eickelberg O. WNT signaling in lung disease: a failure or a regeneration signal? Am J Respir Cell Mol Biol 2010;42:21-31.

8. Pongracz JE, Stockley RA. Wnt signalling in lung development and diseases. Respir Res 2006;7:15.

9. van Noort M, Clevers H. TCF transcription factors, mediators of Wntsignaling in development and cancer. Dev Biol 2002;244:1-8.

10. Goss AM, Tian Y, Tsukiyama T, et al. Wnt2/2b and beta-catenin signaling are necessary and sufficient to specify lung progenitors in the foregut. Dev Cell 2009;17:290-8.

11. Shu W, Jiang YQ, Lu MM, Morrisey EE. Wnt7b regulates mesenchymal proliferation and vascular development in the lung. Development 2002;129:4831-42.

12. Sen M, Reifert J, Lauterbach K, et al. Regulation of fibronectin and metalloproteinase expression by Wnt signaling in rheumatoid arthritis synoviocytes. Arthritis Rheum 2002;46:2867-77.

13. Zuo F, Kaminski N, Eugui E, et al. Gene expression analysis reveals matrilysin as a key regulator of pulmonary fibrosis in mice and humans. Proc Natl Acad Sci USA 2002;99:6292-7.

14. Collins JJ, Kuypers E, Nitsos I, et al. LPS-induced chorioamnionitis and antenatal corticosteroids modulate Shh signaling in the ovine fetal lung. Am J Physiol Lung Cell Mol Physiol 2012;303:L778-87.

15. Collins JJ, Kunzmann S, Kuypers E, et al. Antenatal glucocorticoids counteract LPS changes in TGF- $\beta$ pathway and caveolin-1 in ovine fetal lung. Am J Physiol Lung Cell Mol Physiol 2013;304:L438-44.

16. Thibeault DW, Mabry SM, Ekekezie II, Truog WE. Lung elastic tissue maturation and perturbations during the evolution of chronic lung disease. Pediatrics 2000;106:1452-9.

17. Dasgupta C, Sakurai R, Wang Y, et al. Hyperoxia-induced neonatal rat lung injury involves activation of TGF-\{beta\} and Wnt signaling and is protected by rosiglitazone. Am J Physiol Lung Cell Mol Physiol 2009;296:L1031-41.

18. Wolfs TG, Jellema RK, Turrisi G, Becucci E, Buonocore G, Kramer BW. Inflammation-induced immune suppression of the fetus: a potential link between chorioamnionitis and postnatal early onset sepsis. J Matern Fetal Neonatal Med 2012;25:Suppl 1:8-11.

19. Eastman Q, Grosschedl R. Regulation of LEF-1/TCF transcription factors by Wnt and other signals. Curr Opin Cell Biol 1999;11:233-40.

20. Been JV, Zimmermann LJ. Histological chorioamnionitis and respiratory outcome in preterm infants. Arch Dis Child Fetal Neonatal Ed 2009;94:F218-25.

21. Kramer BW, Kramer S, Ikegami M, Jobe AH. Injury, inflammation, and remodeling in fetal sheep lung after intra-amniotic endotoxin. Am J Physiol Lung Cell Mol Physiol 2002;283:L452-9.

22. Mucenski ML, Wert SE, Nation JM, et al. beta-Catenin is required for specification of proximal/distal cell fate during lung morphogenesis. J Biol Chem 2003;278:40231-8.

23. Zhang M, Shi J, Huang Y, Lai L. Expression of canonical WNT/ßCATENIN signaling components in the developing human lung. BMC Dev Biol 2012;12:21. 
24. Königshoff M, Balsara N, Pfaff EM, et al. Functional Wnt signaling is increased in idiopathic pulmonary fibrosis. PLoS ONE 2008;3:e2142.

25. Kikuchi A, Yamamoto H, Kishida S. Multiplicity of the interactions of Wnt proteins and their receptors. Cell Signal 2007;19:659-71.

26. Cadigan KM, Liu YI. Wnt signaling: complexity at the surface. J Cell Sci 2006;119(Pt 3):395-402.

27. Guo X, Ramirez A, Waddell DS, Li Z, Liu X, Wang XF. Axin and GSK3control Smad3 protein stability and modulate TGF- signaling. Genes Dev 2008;22:106-20.

28. Flozak AS, Lam AP, Russell S, et al. Beta-catenin/T-cell factor signaling is activated during lung injury and promotes the survival and migration of alveolar epithelial cells. J Biol Chem 2010;285:3157-67.

29. Volckaert T, Dill E, Campbell A, et al. Parabronchial smooth muscle constitutes an airway epithelial stem cell niche in the mouse lung after injury. J Clin Invest 2011;121:4409-19.

30. Villar J, Cabrera NE, Valladares F, et al. Activation of the Wnt/B-catenin signaling pathway by mechanical ventilation is associated with ventilatorinduced pulmonary fibrosis in healthy lungs. PLoS ONE 2011;6:e23914.

31. Kuypers E, Collins JJ, Kramer BW, et al. Intra-amniotic LPS and antenatal betamethasone: inflammation and maturation in preterm lamb lungs. Am J Physiol Lung Cell Mol Physiol 2012;302:L380-9.

32. Smith E, Frenkel B. Glucocorticoids inhibit the transcriptional activity of LEF/TCF in differentiating osteoblasts in a glycogen synthase kinase-3betadependent and -independent manner. J Biol Chem 2005;280:2388-94.
33. Takayama S, Rogatsky I, Schwarcz LE, Darimont BD. The glucocorticoid receptor represses cyclin D1 by targeting the Tcf-beta-catenin complex. J Biol Chem 2006;281:17856-63.

34. Been JV, Rours IG, Kornelisse RF, et al. Histologic chorioamnionitis, fetal involvement, and antenatal steroids: effects on neonatal outcome in preterm infants. Am J Obstet Gynecol 2009;201:587.e1-8.

35. Been JV, Degraeuwe PL, Kramer BW, Zimmermann LJ. Antenatal steroids and neonatal outcome after chorioamnionitis: a meta-analysis. BJOG 2011;118:113-22.

36. Harding JE, Pang J, Knight DB, Liggins GC. Do antenatal corticosteroids help in the setting of preterm rupture of membranes? Am J Obstet Gynecol 2001;184:131-9.

37. Gopalani S, Krohn M, Meyn L, Hitti J, Crombleholme WR. Contemporary management of preterm premature rupture of membranes: determinants of latency and neonatal outcome. Am J Perinatol 2004;21:183-90.

38. Hummler SC, Rong M, Chen S, Hehre D, Alapati D, Wu S. Targeting glycogen synthase kinase-3ß to prevent hyperoxia-induced lung injury in neonatal rats. Am J Respir Cell Mol Biol 2013;48:578-88.

39. Moss TJ, Nitsos I, Knox CL, et al. Ureaplasma colonization of amniotic fluid and efficacy of antenatal corticosteroids for preterm lung maturation in sheep. Am J Obstet Gynecol 2009;200:96.e1-6.

40. Livak KJ, Schmittgen TD. Analysis of relative gene expression data using real-time quantitative PCR and the 2(-Delta Delta C(T)) Method. Methods 2001;25:402-8. 